\title{
Interpersonal Meaning of Mood and Modality in English Public Service Advertising Texts
}

\author{
Huiqun Yu \\ Nanjing Forestry University, China \\ huiqun0913@163.com
}

Keywords: Mood; Modality; English public service advertising

\begin{abstract}
English public service advertisements (PSAs) are aimed to provide information of social problems and persuade readers to take positive actions. On the basis of Halliday's systemic functional grammar, this paper probes into the interpersonal meaning of mood and modality in PSAs texts. Advertisers prefer to choose three main kinds of mood: declarative, interrogative and imperative. It is found that the main function of declarative is to give information. Interrogative and imperative make texts more interactive, involving readers and attracting their attention. Then the study reveals that advertisers tend to influence readers' attitudes and behavior through controlling modality. By studying the selection and usage of mood and modality in discourse, the personal meaning of English PSAs texts can be better understood and evaluated.
\end{abstract}

\section{Introduction}

Systemic Functional Linguistics was founded by Halliday in 1960s. Halliday views language as a product of social activity. In term of functional grammar, language system has variety of meaning and presents the most fundatmental functions of language [1]. And one of the important components in Halliday's functional grammar is the meta-functions. Halliday classified it into three kinds: textual function, interpersonal function and ideational function. It aims to reveal that language is a means of social interaction, based on the position that language system and the forms that make it up are inescapably determined by the uses or functions which they serve. The main interpersonal function embodies all uses of language to express social and personal relations. This includes the various ways the speaker enters a speech situation and performs a speech act. Literally, language is used by the speaker to exchange information or services among people, or to establish and maintian social relationships; on a deeper level, the interactions will influence the behavior and judgments of other people and reveal the speaker's attitudes in a certain case or purpose of certain action [2]. The interpersonal function of language represent that the speaker as a participant has potential meaning in the communication. The speaker is using the semantic factor to express his attitude or judgment and affect the views and actions of readers. Publie service advertisements (PSAs) aim to inform the publie of those important social issues and problems, to attract people' $s$ attention on these things and stimulate their positive action to take part in the campaign to solve these significant issues [3]. The purpose of is for the benefit of the public, rather than individual advertisers. Different from commercial advertising, PSAs concern social problems, such as environmental protection, epidemic prevention and social security etc.. They are closely related to readers, so they will take action for their profit. This paper analyzes the interpersonal meaning of mood and modality in PSAs texts. To be simple, the interpersonal function means that the language serves as a significant medium within people's everyday interaction. And it not only shows the speaker's literal meaning and inner activities, but also embodies the speaker's identity, status, attitudes and motivaiton, even influences the attitudes or actions of others [4]. 


\section{Mood in PSAs Texts}

In the acting of speaking, the speaker adopts for himself a particularly speech role, and in so doing assigns to the listener a complementary role which he wishes him to adopt in his turn[5]. That means mood can imply the speakers' roles in a certain discourse and therefore show us their relationships. And mood is composed of two basic elements: subject and finite. The rest of the clause is called residue. The subject can be a noun, a noun phrase, or a clause. The most fundamental purposes in any exchange are giving (and taking) or demanding (and being given) a commodity of some kind. If we look at this from the point of view of a speaker in a verbal exchange, the commodity that the speaker may be giving or demanding is information. We end up with four basic speech roles: giving information, demanding information, giving goods-\&-services and demanding goods-\&-services. The four basic speech functions are closely associated with praticular grammatical sturcrturs. Statements are most naturally expressed by declaratives;questions by interrogative clauses; commands by imperative clauses; offers by modulated interrogative clauses[6]. On the one hand, PSAs provide important information of social issues to the public; on the other hand, it is to persuade the reader to take positive action to solve the problem. In order to achieve these goals, the advertisers have to establish certain relationship with readers through various strategies. In this process, the choice of mood plays an important role. Declarative mood, interrogative mood and imperative mood will be studied to reveal the relationship between advertisers and readers.

Declarative Mood in English PSAs Texts. In English PSAs text, declarative sentences are used the most frequently, especially those simple positive declarative sentences. The declarative mood is the most common way of providing information in PSAs. Moreover, the advertising message can be communicated clearly and correctly, and can emphasize key information and repeat it.

Example (1):

How long are you going to continue watching this show?

Many Portuguese homes are the stage for domestic violence. An unacceptable show in no way suitable for children and tragically, the final act is very often, death. Domestic violence is the fourth most registered crime in Portugal. Watching all this in silence is to turn a blind eye to the violence, it is being a puppet in the hands of the aggressor. Speak out against domestic violence. Don't be part of the audience, be part of the solution.

(http://www.hongkiat.com/blog/creative-public-awareness-ads/)

The example is a PSA named "Stage for Domestic Violence". Three declarative sentences are used to transmit the information about how Portuguese homes suffered from the domestic violences. After giving these persuasive information, the advertiser sincerely ask readers to give hands to fight against domestic violence. As an information-supplier, the advertiser is giving information as a nice friend does, and this PSA is the combination of both authoritative information and kind invitation.

At the same time, it is found that the elliptical declarative sentences are also used to provide information in contemporary English PSAs text, like the underlined sentences in example (1). People generally believe that the use of elliptical sentence is to save time, space and even money. However, functional linguistics hold that any choice is meaningful. More less contact means more using of dominant semantic, and more using of contact means more information can be omitted. Contact is concerned with the degree of involvement among interlocutors. This is determined by the nature of the fields speaker/listeners are participating in —_ how much contact they involve[7]. However, the hidden meaning is still there. In fact, the pace of people's lives continues to accelerate, and they have not so much time to stop and read the entire contents of the PSAs. The eye-catching and succinct few words will be able to catch people's attention.

Interrogative Mood in English PSAs Texts. Interrogative mood is less frequently used mood in PSAs. In PSAs, the original functions of interrogatives for asking questions and seeking answers have been lost, the new function is to attract the audience's concentration as well as to enhance the impression of the discourse for audience[8]. 
It emphasizes the advertiser's opinion but not the demanding information. It can attract readers' attention, and prompt readers to think about the issues raised in the text, and pull readers into the advertising scene, and inspire readers to examine their behavior and thought, making them realize problems they did not notice before. This can help to shorten the distance between the advertiser and readers. Therefore, readers will be more likely to take actions as expected. In fact, there are two basic cases of interrogative mood: WH-interrogatives and yes-no interrogatives.

Example (2):

What's the difference?

Parasite criminal, foreign trash, pig troublemaker, freeloader, vermin, slacker, scum, refugee, you, me.

Nasty names. Shocking even, in print. But all too common if you're unlucky enough to be a refugee.

Wait! Why are "you " and "me " among them? And why is every figure identical? They are all the same!

Exactly!

You see, refugee are like you and me. So what's the difference?

Really only one: fear.

(Newsweek, May 3, 1999)

The question: "What's the difference?" at the beginning, successfully draws the attention of readers. Then, the advertiser lists lots of nasty names in society even including "you" and "me". Why are "you" and "me" among them? This interrogative makes readers think about the answer and thus the advertiser builds a close relationship with readers, then comes the question "what's the difference" again to arouse the public to take good care of refugees before it's too late.

In a word, the interrogative mood used in the text functions to set up a more spoken style and a face-to-face mode to attract the reader's attention, raise his interests to the related topics to continue his reading and shorten the interpersonal distance between the advertiser and the reader.

Imperative Mood in English PSAs. The ultimate goal of PSAs is to persuade readers to take positive and effective action, and the most direct way of persuading is imperative. In PSAs, the imperative mood is only used as persuasion, advice or requirements.

Example (3):

Imagine a fire burning in your home, with your family fast asleep. Smoke and heat intensify quickly. Every second counts. How will everyone escape? Without a plan, you may not know the best route to safety.

Create an escape plan and make sure everyone in your home practices it. Plan two routes of escape from every room, and designate a meeting place outside of the home. Remember: get out and stay out.

This message is brought by the United States Fire Administration. The advertiser uses the imperative sentences to persuade, advise and require people to make a plan before the fire burning.

Advertisers tend to choose the imperatives, which begin with "let's". In PSAs, "let's" is also used to persuade readers to take actions. These kinds of imperative are called inclusive imperatives, because their subjects are not "you", but "you" (the advertisers) and "me" (the readers).

\section{Modality in PSAs Texts}

The modality is another major component of interpersonal function. Halliday holds that modality is a form of participation by the speaker in the speech event. Modality specifies if the speaker is expressing his judgment or making a prediction.

Type of Modality in English PSAs. If the commodity being exchanged is information, the modality relates to how valid the information is in the terms of probability (how likely it is to be true) or usuality (how frequently it is true ) [9]. In the cases of PSAs, there are five main categories: probability, usuality, obligation, willingness and ability/potentiality. Halliday holds that modality 
system can be divided into two main parts: modalization and modulation. Modalization refers to the speaker's judgment for probability and usualness of a theme. Modalization is composed of obligation and willingness, and it refers to the speaker's judgment for the willingness of a theme. Besides these four elements which should be considered into probing the advertisements, abilitylpotentiality is also an important field.

In the forty PSAs, which are randomly selected from the network and magazines (Table 1), 26\% of modality verbs means probability. To avoid absolute statements, advertisers would like to add objection and accurateness in the text, and make their statements accepted by readers, or those statements cannot be effective to persuade readers to act.

Table 1 Distribution of modality in cases

\begin{tabular}{|c|c|c|}
\hline Type & Number & Proportion (\%) \\
\hline Probability & 13 & $28.9 \%$ \\
\hline Usualness & 1 & $2.2 \%$ \\
\hline Obligation & 7 & $15.6 \%$ \\
\hline Willingness & 6 & $13.3 \%$ \\
\hline Ability / Potentiality & 18 & $40 \%$ \\
\hline Total & 45 & $100 \%$ \\
\hline
\end{tabular}

Sometimes, to save readers' faces, advertisers accept readers' disagreement with their opinion. In the example, "maybe" reflects the negative politeness because the advertiser does not force readers to accept his opinion. Then, the most common way of using modality is ability/potentiality, about $40 \%$. It aims to arouse readers' attention to the problem, and call on them to do something.

Besides, the obligation is also very common in the cases of PSAs. The terminal goal of the advertisement is to provide common interest to everyone. And most of the issues are closely connected with daily lives of the public. So to solve the problems, everyone should provide his/her hands. And it is important to stress the obligation of the public. Advertisers use the obligations frequently to make readers notice their own responsibilities on their shoulders, and add a sense of mission to them.

Value of modality in English PSAs. Modality involves degrees and scales. The advertiser may, for example, signal a higher or lower degree of certainty about the validity of a proposition. It is possible to formalize this to some extent and to establish three basic values on the scale: high, median and low [10].

In the forty PSAs, median and low value of probability occupies a great part, about 52.4\%. Meanwhile, high and low value of obligation are used frequently too, about $40.5 \%$.

Table 2 Distribution of the value of probability and obligation in cases

\begin{tabular}{|c|c|c|c|c|c|}
\hline type & value & word & time & total & proportion \\
\hline \multirow{7}{*}{ probability } & high & Can't & 1 & 1 & $2.3 \%$ \\
\hline & \multirow{2}{*}{ median } & will & 6 & \multirow{2}{*}{7} & \multirow{2}{*}{$16.7 \%$} \\
\hline & & would & 1 & & \\
\hline & \multirow{4}{*}{ low } & may & 3 & \multirow{4}{*}{15} & \multirow{4}{*}{$35.7 \%$} \\
\hline & & might & 2 & & \\
\hline & & can & 9 & & \\
\hline & & could & 1 & & \\
\hline \multirow{5}{*}{ obligation } & \multirow{2}{*}{ high } & must & 4 & \multirow{2}{*}{6} & \multirow{2}{*}{$14.3 \%$} \\
\hline & & Have to & 2 & & \\
\hline & median & should & 2 & 2 & $4.8 \%$ \\
\hline & \multirow{2}{*}{ low } & can & 10 & \multirow{2}{*}{11} & \multirow{2}{*}{$26.2 \%$} \\
\hline & & could & 1 & & \\
\hline total & \multicolumn{4}{|c|}{42} & $100 \%$ \\
\hline
\end{tabular}


As can be seen from the statistics above, low value probability and obligation take up the largest part, counting for $61.9 \%$, those with median value taking up the second largest proportion of $21.5 \%$. Probability and obligation used are mainly concerned with the probabilities of something and the obligation of readers in the problem solving. The advertiser uses a large scale of low and median probability and obligation to avoid swearing to everything or absolutizing everything.

The use of low value probability and obligation shows that the advertiser's low commitment to his statement. For example:

(4)You may not have noticed, but fish have gradually have been getting smaller and smaller. (Newsweek, March 24, 2003)

(5)If you think you might be eligible to file a claim, please access the Farmer and Rancher Call Canter or Website:1-888-508-4429 (http://ofbf.org/policy-and-politics/article/440/)

(6)Hunger can be ended if we each make a commitment in our hearts to help. Then we must together to make it happen.(TIME, January 13, 2003)

(7)Saving water is so easy and the savings can be enormous. Saving the sea is a little harder but each one of us can make a difference.(Newsweek, October 14, 2002)

(8)Trillions are being spent on financial rescue packages. Just $1 \%$ of that could turn hunger into hope for 59 million hungry school children. (Fortune, April 13. 2009)

In the examples, "may", "might", "can", and "could" are deployed as the low value probability and obligation. In example (4), "may" can be paraphrased as "it is possible that ...", manifesting the probability of the issue. And in example (5), "might" suggests possibility which is quiet low, even lower than "may"___ those issues may happen or may not happen but the advertiser has to inform readers. In example (6), "can" means possibility and in (7) "can" means ability. By employing "can" in the sentences, the advertiser increases his reliability of illustrating the issue. In example (8), "could" means the possibility or ability.

As the second largest proportion, median value probability and obligation takes up $21.5 \%$. It suggests a median degree of certainty about the validity of a statement, mainly including "will", "would", "should". For example:

(9)Vestas has installed more than one third of all wind turbines in the world and we predict that $10 \%$ of the global electricity consumption will be covered by wind energy 2020.(TIME, April 28, 2008)

(10)Unless the EU closes the Mediterranean bluefin tuna fishery immediately, fishing communities as well as the wider marine ecosystem would be put at risk.(Fortune, February 2.2009)

(11)This isn't just expediency ; it's how WWF believes conservation projects should be run.(Newsweek, June 18, 1998)

The "will" in the above example indicates the message about something that is going to happen exactly in the future. In the example, "should" conveys a median degree of pressure on the reader to carry out actions. All in all, the advertiser uses these probability and obligation to express his certain attitudes toward the problems that he mentions.

High value probability "can't" and obligation "must" and "have to" typically indicate a very strong obligation. The advertiser uses explicit orientation to show his judgment about inclination or obligation on some certain issues. In the selected data of materials in PSAs, high value mood does not ring so widely_ taking up only $16.6 \%$, which means it is rarely seen that the advertiser uses explicit subjective orientation to indicate his judgment about inclination and obligation on some related issues.

\section{Conclusion}

This paper analyzes the personal meaning of mood and modality in English PSAs texts. The study finds that giving information is primarily expressed by declarative mood, and demanding action is dominantly realized by imperatives and interrogatives. Then the study reveals that most of probability expressions are low value for increasing reliability of the text and showing politeness to readers. And 
most of high value expressions are obligation, which can reflect an unequal social status between advertisers and readers. By means of such modal expressions, advertisers can persuade readers to take positive actions.

\section{References}

[1] M.A.K. Halliday: Language as Social Semiotic: The Social interpersonal Interpretation of Language and Meaning (Foreign Language Teaching and Research Press, China 2001), p.187.

[2] G. Thompson: Introducting Functional Grammar (2nd Edition) ( Foreign Language Teaching and Research Press, China 2008), p.46.

[3] Y.Q. Fang: Interpersonal Meaning of Mood System in English Public Service Advertising Texts (MS., Xiamen University, China 2009),p.1.

[4] W.P.Tang: A Corpus-based Study of Interpersal Function in A Study in Scarlet (MS.,Southwest Petroleum University, China 2016 ),p.6.

[5] M.A.K. Halliday: An Introduction to Functional Grammar (Edward Arnold, United Kingdom 1994), p. 68.

[6] S. Yang: Interpersonal Meaning of Public Service Advertising Texts---A Systemic Functional Approach (MS., Guangdong University of Foreign Studies, China 2006),p.31.

[7] J.R. Martin: English Text: System and Structure (Benjamins, Netherland 1992), p.530.

[8] T.Y. Guo: A Study of Interpersonal Functional of Mood in English Public Service Advertising Discourse (MS., Jilin University, China 2014), p.31.

[9] G.Thompson: Introducing Functional Grammar (Foreign Language Teaching and Research Press, China 2000), p.57.

[10] M.A.K. Halliday: An Introduction to Functional Grammar (Edward Arnold, United Kingdom 1994), p. 358. 